NBER WORKING PAPERS SERIES

NATIONAL HEALTH INSURANCE REVISITED

Victor R. Fuchs

Working Paper No. 3884

NATIONAL BUREAU OF ECONOMIC RESEARCH

1050 Massachusetts Avenue

Cambridge, MA 02138

October 1991

Prepared for Health Affairs, Winter 1991. Henry J. Kaiser, Jr. Professor, Stanford University, and Research Associate, National Bureau of Economic Research. Comments from Andrew Batavia, Alan Garber, Donald Redelmeier, and Joanne Spetz are gratefully acknowledged. This paper is part of NBER's research program in Health Economics. Any opinions expressed are those of the author and not those of the National Bureau of Economic Research. 
NBER Working Paper \#3884 October 1991

NATIONAL HEALTH INSURANCE REVISITED

\begin{abstract}
This paper explains why one in seven Americans has no health insurance, and compares the casualty and the social insurance models of health insurance. The paper discusses the relationship among national health insurance (NHI), the cost of care, and the health of the population, and it considers the prospects for NHI in the United states in the short and the long run. Four explanations for the absence of NHI in the United States -distrust of government, heterogeneity of the population, a robust voluntary sector, and lack of noblesse oblige -- are evaluated in the light of recent political, social, and economic trends:
\end{abstract}

Victor R. Fuchs

NBER

204 Junipero Serra

Boulevard

Stanford, CA 94305-7639 


\section{NATIONAL HEALTH INSURANCE REVISITED}

Victor R. Fuchs

Proposals for national health insurance (NHI) are once again making the headlines, as they have periodically in the United States since World War I. ${ }^{1}$ The advocates of NHI have, as always, diverse goals: to increase access for millions of Americans who do not have health insurance; to stem the rapid escalation in the cost of care; to improve the health of the population and reduce socioeconomic differentials in ife expectancy. Vigorous opposition to NHI is also not a new phenomenon. Insurance companies, physicians, and others directly involved in the health field see it as a threat to their roles and Interests; in addition, many Americans with no direct Involvement oppose expansion of government on general principles. The huge budget deficit contributes to the difficulty of enacting a major new domestic program, in health or any other area.

How and when will the current debate over health policy be resolved? Fifteen years ago I discussed the popularity of NHI around the world and offered four reasons why the United States was the last major holdout. ${ }^{2}$ They were: distrust of government; heterogeneity of the population; a robust voluntary sector; and less sense of noblesse oblige. In this paper I consider whether these explanations are as relevant today as in the past. First, however, I discuss several issues that help to put the NHI controversy in clearer perspective. Why are so many Americans uninsured? How do conflicting views of health insurance shape attitudes toward NHI? What is the connection between NHI and the cost of care? Would NHI do much to reduce socioeconomic differentials in health? 


\section{The Uninsured}

With some exceptions such as Medicare, health insurance in the United States is a private, voluntary matter. The demand for insurance, like the demand for any good or service, depends on the consumer's abllity and willingness to pay for 1t. Some of the uninsured cannot afford health insurance; others are unwilling to acquire it. In all, they can be grouped into six categories.

1. The poor. The largest group of uninsured consists of individuals and families whose low income makes it unfeasible for them to acquire insurance, either on their own or as a condition of employment. About one in five have no connection with the work force, but nearly 802 are either employed or are the dependents of employed persons. ${ }^{3}$ The HIAA estimates that 317 of these workers earned less than $\$ 10,000$ in 1989 ; another estimate puts the figure at $63 \% .4$ In any case, it is clear that the great majority of uninsured workers cannot afford to give up a substantial fraction of their wages in order to obtain health insurance.

Most uninsured workers are employed in small firms, but the frequently heard explanation, "Small employers can't afford health Insurance," is as misleading as the phrase "employer-provided health insurance." Employers don't bear the cost of health insurance; workers do, in the form of lower wages or foregone other benefits. A more accurate description of the problem would be "many workers in small firms can't afford health insurance." Note that lawyers, accountants, computer consultants, and other highly paid professionals organized in small firms usually have health insurance, although they often face extra costs as discussed below. 
2. The sick and disabled. Many men and women who are not poor are still unable to afford health insurance because they have special health problems and therefore face very high premiuns or are excluded from some coverage entirely. 5

3. The "difficult". Some individuals are neither poor nor sick, but have difficulty obtaining insurance at average premiums. They may be selfemployed, work in small firms, or are out of the labor force entirely. In order to reach and service such individuals, insurance companies incur abnormally high sales and administrative costs. They also encounter the problem of adverse selection: if an insurance company offers a policy to individuals or small groups at an average premium, those who expect to use a great deal of medical care are likely to buy, and those who do not will refrain from buying.

4. The low users. Some people don't expect to use much medical care . They may be in particularly good health; they may dislike going to physicians; or, like Christian Scientists, they may not believe in the efficacy of medical care. For them, health insurance is a "bad buy" unless they can acquire it at a below-average premiun.

5. The gamblers. Most people buy health insurance in part because they are risk averse. They would rather pay a fixed, known premium (even including a charge above the actuarial level) than run the risk of a huge expense in event of serious illness. But not everyone is risk averse about health expenditures, or risk averse to the same degree. The gambler says "I'd rather save the premium and take my chances."

6. The free-riders. The final category consists of individuals who remain uninsured because they believe that in the event of serious illness 
they will get care anyway, with somebody else picking up the bill. They save the cost of insurance and "free ride" on the coattails of those who do pay into the health care system. There may be elements of "free riding" in the behavior of the low users and the gamblers as we11; it is often difficult to distinguish among these three categories of individuals who are able to pay for insurance but are unwilling to do so.

Review of the six categories reveals that achievement of NHI is, from an analytical perspective, rather simple; all it requires is subsidization of those who are unable to afford insurance and compulsion for those who are unwilling to acquire it. No country in the world achieves universal coverage without subsidization and compulsion. The best short explanation of why the United States does not have universal coverage is that the majority of Americans have resisted subsidizing those who are unable to afford insurance and have been reluctant to force coverage on those who do not obtain it voluntarily. 6

\section{Two Models of Health Insurance}

Part of the current debate over NHI is rooted in two conflicting visions of how the cost of health care should be shared. We can designate one as the casualty model and the other as the social insurance model. Casualty insurance, which usually refers to automobile collision, residential fire, and similar risks, is premised on the idea that premiuns should (to the extent feasible) be set according to expected loss. Other things equal, policy holders who have better driving records or put smoke detectors in their homes pay lower premiums, while poorer risks pay higher premiums. Social insurance, 
which is the basis for NHI, provides for extensive cross-subsidization across different risk groups; it ignores expected loss in allocating costs.

As applied to health insurance, advacates of the casualty approach argue that it is more efficlent and more equitable than social insurance. They assert that utilization of care depends, to some extent, on personal behavior and choice. If premiums vary with expected utilization, Individuals have an incentive to choose healthier behaviors and to be more cost conscious in their utilization of care for any given health condition. ${ }^{7}$ A clear example of the former is charging cigarette smokers a higher premium than nonsmokers. This may decrease the number of smokers, and even if it doesn't, the casualty model advocates argue that it is fair for smokers to bear the extra cost of their unheal thy habit.

Even when there is no possibility of altering behavior, and even if the utilization of care is unrelated to insurance coverage, there is still an efficlency advantage for the casualty model in any system of voluntary health insurance. The alternative, a uniform premium for all individuals, including those with major health problems, will discourage purchase of insurance by those without such problems because the premium for them is unreasonably high. Arguments for the social insurance model rely heavily on appeals to justice, that is, to a sense of collective responsibility. In earlier times these feelings of mutual responsibility were often evident within families and within religious communities. In modern times many countries have extended it to encompass the entire nation. The philosophical foundation can be discerned in John Rawls's discussion of making cholces behind a vell of ignorance." Suppose before you were born you didn't know if you were going to be rich or poor, sick or healthy; you might (assuming some risk aversion) prefer to be 
born into a society that would provide health care for, say, persons born with a genetic disease on the same basis as those born without such a problem. Advocates of the social insurance model also point to efficiency arguments. Because everyone must participate, there can be savings in sales and administrative costs that offset other efficiencies achieved through the casualty approach.

Whether the casualty or the social insurance model is more conducive to an efficient health care system is primarily an empirical question (interwoven with value judgments) that cannot be answered a priori. Which approach is more just is primarily a value question (Individual versus collective responsibility), but empirical information concerning the reasons for variation in utilization of care is relevant. In my experience, the same audiences that overwhelmingly approve charging smokers a higher premium because they use more care, strongly oppose a premium surcharge for individuals whose high use is attributable to genetic factors. Should cigarette smoking turn out to have a significant genetic component, opinions concerning the smoker surcharge would presumably change. One consequence of the genetics revolution may be to shift public sentiment toward the social insurance model.

NHI and the cost of Care

Opponents of NHI frequently assert that universal coverage would result in a substantial increase in the total cost of care. Both theoretical and empirical research support the view that the lower the price of care to the patient, the more care he or she will want to receive. The logic of this argument suggests that those countries with universal coverage should be 
spending more on medical care than does the United States. In fact, the reverse is true. On a per capita basis, and adjusting for differences in real Income, the United States spends much more on medical care than any other country. For instance, the average American spends about $40 x$ more than the average Canadian, even though the difference in real income per capita is less than 10x. And Canada spends more per capita than does any European country. How can this be? The following discussion shows that countries with universal coverage find other methods to contain health care spending, methods that appear to be more effective than relying on financial constraints on patients.

The most obvious source of saving under NHI is in health insurance administration. In the United States approximately six percent of national health expenditures is accounted for by "program administration and net cost of private health insurance." To this must be added several additional percentage points for costs incurred by providers for billing and other administrative activities directly attributable to the American system of financing care. By contrast, the Canadian system of provinclal health insurance imposes minimal administrative and billing costs on providers and payors; the insurance plans themselves are inexpensive to run because everyone must join and premiums are collected through the tax system.

But savings in administrative costs are only part of the answer. Nearly all countries with NHI rely heavily on what I call "upstream resource allocation" (URA). The key to URA is control over capital investment in facliticles and equipment, specialty mix of physicians, and the development and diffusion of high-tech, high-cost technologies. Such control usually results in less excess capacity, both in physical and human capital. In Canada, for 
instance, relatively scarce high-tech equipment, such as MRI's or CT scanners, is used Intensively, while the proliferation of such equipment in the United States results in considerable idle time. There are more phystcians per capita in Canada than In the United States, but there are many fewer who specialize in complex surgical and dlagnostic procedures. As a result, the average Canadian specialist has a full workload, whlle his or her American counterpart does not. ${ }^{\circ}$

The price that Canadians and Europeans pay for such controls is delay or inconvenience in obtaining access to high-tech services, and in some cases not receiving such services at all. Whether such delays or denials have a significant effect on the health of the population is not known with certainty; the limited evidence currently available suggests that they do not. Another way that forelgn countries with NHI contain costs is by using their centralized buying power to squeeze down the prices of resources, especially for drugs and physicians' services. Drug prices in the United States usually contain significant monopoly rents as evidenced by the willingness of the drug manufacturers to sell the Identical products overseas at much lower prices.

Canadian and European physicians do not enjoy as high net incomes as do American physicians, even after adjustment for international differences in the general level of wages. But this does not mean that American physicians are more satisfled with their lot or that American medical schools find it easier to attract high quality, well motivated applicants. Compared to physicians in most countries with NHI, American physicians suffer more bureaucratic supervision froin public and private insurance plans and more interference with the day-to-day practice of medicine. 
It is Important not to overestimate the amount of money that can be saved by squeezing physiclans. In the United States physicians' net incomes account for approximately $10 \%$ of all health care spending. Suppose these incomes could be reduced by $20 x$ (the approximate differential between the United States and Canada after adjusting for specialty mix, the exchange rate, and the general level of wages). ${ }^{10}$ The saving would be $2 x$ of health care spending, and even this is not a saving of real resources but only a money transfer from physiclans to patients and taxpayers.

Cost containment under NHI often relles on single source funding set prospectively. An example is the global budget given to each Canadian hospital at the beginning of each year. Samuel Johnson sald, "When a man knows he is to be hanged in a fortnight, it concentrates his mind wonderfully." Much the same seems to be true of health care. When physicians and hospital administrators know that there is a certain pool of resources at their disposal and that no more will be forthcoming, they seem to figure out ways to do the Job with what they have. To be sure, this inevitably involves limitation of some services, but most health professionals prefer having some control over the allocation of the scarce resources that are available to them.

\section{NHI and Health}

Does NHI improve the health of the population by increasing access to care? Or does it worsen health by constraining the introduction of new technology and destroying incentives for physicians and hospitals? There is no conclusive answer to this question; in my judgment NHI has little effect on health one way or the other. ${ }^{12}$ 
With regard to the other stated health goal--the reduction of differentials in health outcomes within a country--the evidence is more compelling. Universal coverage for medical care does not eliminate or even substantially reduce differentials across socioeconomic groups. In England, for instance, infant mortality in the lowest socioeconomic class is double the rate of the highest class, just as it was prior to the introduction of NHI. ${ }^{13}$ The relatively homogeneous populations of Scandinavia not only enjoy universal coverage for health care, but also have many other egalitarian soclal programs. Nevertheless, life expectancy varies considerably across occupations; the age-standardized mortality ratio for male hotel, restaurant, and food service workers is double that of teachers and technical workers. ${ }^{14}$ In Sweden a study of age-standardized death rates among employed men ages 4564 found substantial differentials across occupations in 1966-70 and slightly greater differentials in $1976-80.15$ The author adds "There is no systematic evidence that the health care system is inequitable in the sense that those in greater need get less care, or that there are barriers towards the lower socioeconomic groups"(p. 13).11

Is the failure of NHI to eliminate or reduce mortality differentials a decisive argument against its adoption? Not necessarily. Bruce Vladeck. argues that curing disease and improving functional outcomes are not the only benefits of medical care. He writes "We expect the health systern to take care of sick people whether or not they are going to get better, as much for our beneflt as theirs." 16 The caring and validation services provided by health professionals have value even when they do not change health outcomes. ${ }^{17}$ 


\section{Prospects for NHI in the United States}

What changes have occurred since 1976 that might modify the relevance of the four reasons I advanced to explain the absence of NHI in the United States?

1) Distrust of government. It seems 1ikely that the typlcal American's distrust of government is stronger now than it was in the mid-1970s. Jimmy Carter was elected as an "outsider," and he did little to enhance the image of the Presidency or of government in general during his four years in office. Ronald Reagan maintained an anti-government posture throughout his two terms. George Bush may be more pragmat1c and less 1deological, but he still commands wide support with the message "government is the problem, not the solution."

Can our political institutions deal with a complex problem such as health care efficiently and honestly? The recent experlence with the savings and loan industry provides ample cause for concern. This debacle did not, like a major earthquake, come upon us suddenly. It was a well-diagnosed, localized cancer that government allowed to metastasize to 1 ts present level. What is particularly disturbing is that the blame cannot be laid at the door of one political party--both Democrats and Republicans helped the cancer to spread. Moreover, it was not the fault of just one branch of government; both Congress and the Executive Branch are fully 1mplicated. Finally, it was not just the Federal government that was derelict; state regulatory agencies and state legislatures also failed to meet their responsibilities to the public. Our government is built on checks and balances: by political parties, by branches of government, and by levels of government. If these checks and balances failed so badly with savings and loans, many observers wonder how 
we11 they would do with health care, which is so much larger, so much more complex, and so much more vulnerable to mismanagement and dishonesty.

2) Heterogeneity of the population. In 1976 I argued that the heterogeneity of the U.S. population helped explain a reluctance to embrace NHI. Unlike the Swedes, Germans, Japanese, and many other "peoples," most Americans do not share centuries of common language, culture, and tradition; thus there is less sense of national 1dentification and empathy. In 1991 this explanation probably has even more force. The celebration of "multiculturalism" in the United States in the past fifteen years appears to have led to a heightened sense of separateness among the country's many ethnic, religlous, and racial groups. Glorification of the "pluribus" at the expense of the "unum" does not enhance the prospects for NHI.

Heterogenelty of values also fuels the resistance to NHI. No nation should expect or desire uniformity of opinion, but the name-calling and physical violence that often accompany debates in the Unfted States over values undermines the ability of the nation to undertake collective efforts for collective well-being. Americans might consider the words of the British historian, R. H. Tawney, "The condition of effective action in a complex civilization is cooperation. And the condition of cooperation is agreement, both as to the ends to which efforts should be applied and the criteria by which its success is to be judged."18

3) A robust voluntary sector. America has always been distinguished from most other nations by its highly developed private, nonprofit Institutions devoted to health, education, and social services. These institutions, often founded and supported by religious groups, perform many of the functions that government undertakes in other countries. During the past 
fifteen years, however, the abllity of nonprofit hospltals and the Blue CrossBiue Shield organizations to provide a form of soclal insurance through free care, cost shifting, and community rating of insurance premiums, has been serlously compromised. The "competition revolution"19 has imposed the casualty approach to health insurance as a condition for survival. The growth of PPOs, HMOs, and tough bargalning by all third-party payors has sharply diminished the capacity of nonprofit institutions to act as redistributive agents. The declining importance of philanthropy relative to private and public health insurance also decreases the ability of the nonprofit Institutions to act as quasi-governmental agencles. In health care the "thousand points of $11 \mathrm{ght}$ " are fainter now than in the past. I conclude that the "voluntary sector" explanation for the absence of NHI in the United States has less force in the 1990 s than it had in an earlier era.

4) Less "noblesse oblige". The two central ideological forces of American society have been a commitment to individual freedom and a commitment, at least in the abstract, to equality. There has always been a tension between these forces, with the emphasis on individual opportunity and achievement prevalling most of the time, but the egalitarian emphasis much in evidence in the 1930s and 1960s. Even the egalitarian ideology, however, has focused more on equality of soclal status, equality under the law, and equality of opportunity, than on equality of outcomes. Because so many Americans of humble origins could and did achieve wealth and position, the sense of "noblesse oblige" that motivates many of the well-born in other countries to vote for social programs to aid the less fortunate has never been as evident in the United States. 
How have the developments of the past fifteen years affected this explanation? I find it difficult to judge, but suspect that it may be slightly more relevant today. During the 1980 s the rhetoric of most of the American right wing was "laissez-faire," not "Tory conservative." Moreover, the left wing's infatuation with the vocabulary of "rights" (divorced from obligations) often diminishes rather than enhances a feeling of mutual responsibility.

In summary, the distrust of government and the population heterogeneity explanations are probably more relevant today than in 1976, and the lack of noblesse oblige may be more relevant. Only one explanation--the robustness of the voluntary sector--is definitely weaker now. It is ironic that the "competicion revolution," which erodes the ability of not-for-profit health care institutions to provide a modicum of social insurance, may prove to be a significant factor leading the country toward NHI.

Will the United States adopt NHI? In my view the prospects in the short run are poor. The forces actively opposed to NHI are strong, well organized, and have a clear sense of what they don't want. The forces actively in favor are relatively weak, disorganized, and frequently at odds regarding the reasons for wanting NHI or the best way to obtain it. The great majority of Americans are not actively involved in the debate one way or the other, but tend to be opposed for the reasons I have indicated. Some public opinion polls seem to indicate a readiness for NHI, but they are not credible indicators of political behavior. For example, one recent survey of business executives reports that they belleve the high cost of health care to be America's most serious problem. At the same time business executives 
overwhelmingly approve of President Bush, who has not made reduction of health care costs a high priority for his administration.

In the long run, NHI is far from dead; the need to curb cost while extending coverage will continue to push the country in that direction. The process will accelerate as nonprofit health care institutions lose their ability to provide some social insurance as an alternative to NHI. Moreover, the current trend of basing insurance premiums on expected utilization will strike more people as unjust because most disease will be found to have a significant genetic component. Also, as employer hiring decisions and employee $j$ ob cholces become increasingly constrained by health insurance considerations, there will be more appreclation of the efficlency advantages of making health insurance Independent of the labor market.

The timing of adoption of NHI will depend largely on factors external to health care. Major changes in health policy, 11ke major policy changes in any area, are political acts, undertaken for political purposes. That was true when Bismarck introduced NHI to the new German state over a hundred years ago. It was true when England adopted NHI after World War II, and it will be true in the United States as well. NHI will probably come to the United States in the wake of a major change in the political climate, the kind of change that often accompanies a war, a depression, or large-scale clvil unrest. Short of that, we should expect modest attempts to increase coverage and contain costs, accompanied by an limodest amount of "sound and fury." 
NOTES

1. NHI can take many forms. The emphasis in this paper is on any national system that provides universal coverage.

2. V. R. Fuchs, "From Bismarck to Woodcock: The 'Irrational' Pursuit of National Health Insurance," The Journal of Law and Economics (August 1976): $347-359$

3. D. Chollet, "Update: Americans without Health Insurance," EBRI Issue Brief (Washington, DC: Employee Benefit Research Institute, July 1990).

4. Health Insurance Association of America, "Providing Employee Health Benefits: How Firms Differ" (Washington, DC, 1990).

5. See, for example, G. DeJong, A. I. Batavia, and R. Griss, "America's Neglected Health Minority: Working-age Persons with Disabilities," The Milbank Quarterly 67 (Supp1. 2, Pt. 2, 1989): 311-351.

6. The united States has some compulsion and some subsidization among the employees of large companies. In the typical case, all workers participate, and the firm rarely adjusts the individual worker's wages or premiuns to take full account of differences in expected utilization.

7. The RAND Health Insurance Experiment clearly showed that utilization is greater when patients do not bear some of its cost. See W. G. Manning et al., "Health Insurance and the Demand for Medical Care: Evidence from a Randonized Experiment," The American Economic Review (June 1.987): 251-277. 
8. J. Rawls, A Theory of Justice (Cambridge, Mass.: Harvard University Press, 1971).

9. V. R. Fuchs and J.. S. Hahn, "How Does Canada Do It? A Comparison of Expenditures for Physicians' Services in the United States and Canada," The New England Journal of Medicline (27 September 1990): 884-890.

10. Ibid.

11. J. Boswe11, Life of Johnson, 1791 (Sept. 19, 1977).

12. The effect of NHI on health depends on the product of two elasticities: 1) the responsiveness of the quantity of medical care to NHI, and 2) the responsiveness of health to changes in the quantity of medical care. In developed countries the product of these terms is apparently very $\operatorname{sma11.}$

13. P. Townsend and N. Davidson (eds.), Inequalities in HeaIth: The Black Report (Harmondsworth, England: Penguin Books, 1982).

14. O. Andersen, "Occupational Impacts on Mortality Declines in the Nordic Countries," in W. Lutz (ed.), Future Demographic Trends in Europe and North America, International Institute for Applied Systems Analysis, Laxenburg, Austria. (New York: Academic Press, Harcourt-Brace-Jovanovich, 1991), p. 46 .

15. J. Callthorp, "The 'Swedish Model' under Pressure," International Journal of Quality Assurance in Health Care, forthcoming. 
16. B. C. Vladeck, "Unhealthy Rations," The American Prospect (Summer 1991): 102

17. V. R. Fuchs, who Shall Live? Health. Economics, and Soclat Ghoice (New York: Basic Books, 1974).

18. R. H. Tawney, Religlon and the Rlse of Capltallsm (New York: Harcourt Brace, 1926).

19. V. R. Fuchs, "The 'Competition Revolution' In Health Care," Health Affairs (Summer 1988): 5-24. 